\title{
Immersive virtual reality to enforce teaching in engineering education
}

\section{Osama Halabi ${ }^{1}$}

Received: 2 December 2018 / Revised: 6 July 2019 / Accepted: 12 September 2019 /

Published online: 4 December 2019

(C) The Author(s) 2019

\begin{abstract}
Prior studies on the use of digital prototyping and virtual reality (VR) in designing as well as evaluating new products have shown that VR reduces both development time and costs whilst augmenting student motivation and creativity. The current study demonstrates that VR and 3D prototyping in the context of project-based learning (PBL) promote effective communication, increase problem solving skills, and enhance learning outcomes. VR and digital prototyping have been extensively used in industries for the purpose of product design and usability evaluation. In the context of engineering education, many research studies have attempted to explore the effect of VR on teamwork, engagement, retention, and motivation. In this paper, VR is used in conjunction with PBL in self-directed approach to design and implement a product using 3D software whilst also using virtual reality immersive CAVE display to evaluate their design. The hypothesis is that the use of VR with a project-based-learning approach to facilitate the attainment of desirable goals in the engineering design project, improved achievement of course learning outcomes and promoted effective communication. According to the research findings, VR approach significantly affected the distribution of cumulative project grades. Students' project grades improved, particularly the implementation component. In addition, the course outcomes related to project design were better achieved in VR approach. The communication and problem-solving skills were improved in the VR approach as compared to traditional approach.
\end{abstract}

Keywords Virtual reality · Interactive learning environments $\cdot 3 \mathrm{D}$ modeling $\cdot$ Project-based learning $\cdot$ First-year students

Osama Halabi

ohalabi@qu.edu.qa

1 Department of Computer Science and Engineering, Qatar University, Doha, Qatar 


\section{Introduction}

Preparing students for the purpose of adapting to futuristic technological discoveries and inventions entails their training to become acquainted with environments $[2,25]$ and interactive training methodologies whose results are comparable to hands-on-training immediately upon their admission into their university. Inextricably, the potential of their bright future is predicated on the implementation of IT and engineering-related concepts [20,21]. Against this backdrop, virtual reality allows for real-time, on-demand visualization as well as interactive features across diverse $3 \mathrm{D}$ virtual worlds which are very similar to real world scenarios $[10$, 24]. Furthermore, recent advancements in VR technology have made it possible to integrate these systems into new game consoles. At the same time, consumer devices are witnessing a widespread proliferation for home usage - signifying a new paradigm shift in the gaming domain. Over the past two years, VR and augmented reality (AR) startups have emerged owing to the technology's potential to affect how people work, exercise, communicate, and learn.

In order to provide an effective self-directed learning-based engineering education, many methods were deployed to foster learning. These methods are inclusive of inquiry-based learning (IBL), project-based learning and team-driven learning (TDL) [13]. Among these, PBL has gained prominence in engineering education wherein students are working across teams to design and deploy projects which are an accurate reflection of their knowledge [8]. Many engineering courses have adopted this approach, either partially $[7,26]$ or in entirety [6].

Since engineers are viscerally problem solvers, they are driven by the need to inculcate creative and critical thinking to either design new products or bring about improvements in existing ones. Therefore, it is critical to engage them meaningfully in creative processes, such as designing a product [9]. Methodologies premised on team work and PBL are being increasingly adopted in education as well as workspace $[16,35]$. The primary objective of including design-based projects in engineering courses (first year) is to help undergraduate students of computer engineering, electrical and mechanics to get acquainted with and apply theories of engineering design processes whilst also encouraging them to consider practical constrains when working on a project. This traditional project style in helping students accomplish these objectives is not without shortcomings. For instance, very often, the project becomes too ambitious, which prevents students from testing or implementing their hypothesis; by the same token, it often becomes so simple that some of these design concepts are of the K-12 level. Consequently, they are unable to implement the design steps in entirety.

The industry realized the importance of VR in digital prototyping, which has been utilized during different phases of design process. Leading companies like Jaguar Land Rover are increasingly integrating the concepts of VR at the designing stage of the New Product Introduction (NPI) process. This in turn facilitates the utilization of implementable 3D digital prototypes in order to make timely decisions at the nascent stages of design. By providing a feasible environment to conduct design reviews, VR reduces time and costs related to developments whilst bringing about improvements in the usability and quality of new products [14]. F-city vehicle was designed by French company (FAM) using VR as convergence tool in the product design process [15]. Automotive industry such as Ford, Hyundai, and Volvo are using VR not only in the building process, but also in sales. VR technologies are also used in consumer product usability due to their efficient user experience and usable evaluation even during the nascent stages of product design [12]. Recent study provided evidence of VR technologies being a promising tool for evaluating contextual influences in food consumer 
research [4]. Therefore, it becomes important to apply this approach in the academic curriculum to enable the students to practice using VR in design and evaluation and prepare them for the challenges that they will encounter in their professional life.

The research presented in [28] showed the manner in which digital fabrication techniques were used wherein ideas that are converted into digital designs using $3 \mathrm{D}$ software and 3D printers present a great opportunity to develop creativity. This is reflected in the fact that the participants' creative competence increased by 24.04 points in the Abreaction Test of Creativity. Using 3D printers to evaluate the design is costly and time consuming. In this paper, we extend the above approach by enabling the students to evaluate their designs using immersive VR. This approach is expected to add creativity as potentially beneficial dimension to the learning process. Recent work by Tan et al. in [32] introduced hybrid PBL (h-PBL) where part of the course still uses traditional lecturing (TL). In h-PBL, the instructor serves as a facilitator in a project, which trained students to collect, analyze and synthesize information and enhance their knowledge. The approach introduced in this paper uses the same concept of self-directed learning by giving the students a chance to learn, apply, test, and analyze their result to enhance their knowledge. It can be considered as the first step towards a new framework for hybrid PBL that can be applied in many courses in which students utilize 3D software to implement their designs and VR as a tool to evaluate their project.

This paper extrapolates on a pilot study involving first year engineering students at the Qatar University, learning engineering and ethics subject as part of a self-directed approach to augment their problem-solving skills and communication skills in addition to enhancing their skills in engineering design. It has been explored with first year students that have no prior knowledge or skills in 3D software or programming. The project's design and development were undertaken by leveraging 3D modeling software, or virtual prototyping. VR immersive CAVE display was also used to help the students examine their design in an intuitive, interactive and immersive virtual ecosystem. The study provides a detailed description of assessment tools and experimental design with statistical analysis of the results of student outcomes using the MWW test to check for significant differences while comparing the means with $95 \%$ confidence interval and standard significance level $p$ value of 0.05 . Detailed description of the task, process, and CAVE display with preliminary result was reported in previous paper [17].

In the past, many research studies have attempted to explore VR, or $3 \mathrm{D}$ modeling and prototyping, albeit to a lesser extent. Belgacem et al. [36] examined how utilizing 3D computational design software (SolidWorks) across undergraduate courses of interdisciplinary nature can provide a robust foundation for the development of both spatial thinking and communication skills. While not much research has been carried out to gauge the impact of immersing VR technique, the feedback and assessment results from the students suggested that the overall quality of team work improved and that the students were highly motivated during the course. The research in [11] presented virtual teaching and learning environment to support the deployment of PBL in teaching "Network Design" for Computer Science. They leveraged gamification strategies in order to boost engagement, retention and motivation. An elevated degree of engagement and motivation was observed without yielding any solid result. In [23] video was combined with $3 \mathrm{D}$ virtual world to link students who were working on a projectcentric engineering design course and seeking guidance from experts within the industry. They pointed out that the engagement with experts increased their motivation for taking part in the exercise. However, large-scale investigations are still required before drawing any concrete conclusion; at the same time no study of eventual project outcomes have been mentioned. 
According to Travassos and his colleagues [34], the design of virtual laboratories related to electrical circuits that helps students gain virtual access to laboratories and collaborate remotely whilst performing the experiments. Although the process of developing 3D models was demonstrated, no evaluation or assessment was accommodated in the process. According to the research in [22] the feasibility to leverage VR as a tool was proven in explaining vital engineering concepts to first year students of engineering. They arrived at the conclusion that the teaching tool does make a significant contribution to enhance the student's retention abilities, although no official results were published. In addition, they utilized a powerful teaching tool in the form of a 3D design podium (VR-based) that is non-immersive. This study entails the utilization of a virtual environment that is completely immersive and accommodates higher interactivity using a large-scale display. The above result is also supported by the study in [18] where using VR in student-led projects across Computer Science (CS) curriculum increased the retention rate from $54 \%$ to $64 \%$ in addition to helping students to express creativity and innovation. The study presented in [29] examined the immersive VR in teaching and training students at medical sector. VR-based learning came on top of other two text and video based learning with result that statistically significant. Lee et al. [3] assessed the potential of desktop VR technologies in enhancing learning and produced a theoretical model as well as a board framework in order to decipher the determining factors of learning efficacy within a desktop VR environment. They found that perceived learning efficacy and satisfaction drastically impacted learning outcomes. Other factors did not have an overtly strong impact on the performance of students. When compared to earlier results, this proposed approach tends to perform better in measurement criteria particularly in terms of presence, control, active learning as well as reflective thinking - all these factors significantly affect learning outcomes. Seo and his colleagues in [30] explored the impact of using VR learning environments for teaching cybersecurity concepts. Simple evaluation using observation and feedback suggested that students' short and long term memory can benefit in engaging manner. As per the research work in [16], a feasible teaching methodology was posited for engineering students in a practical VR course. Although no reliable evolution of the efficacy of VR in influencing overall performance was presented, the motivation levels of students were found to increase. Nevertheless, there are many open source software for creating and sharing virtual environments such as Open Simulator and Second Life that mostly targets web-based VR. Although it is possible to create simple 3D contents and share it with a number of clients, it does not support view and interaction in immersive VR, which is essential for evaluation, and only allows interaction in $2 \mathrm{D}$ desktop display. Also, the editing tools provided are general and not suitable for engineering prototyping.

To summarize, the previous literature identified many aspects where using $3 \mathrm{D}$ and VR technologies in engineering education can enhance learning. It can enhance the development of both spatial thinking and communication skills [18, 36], improve the learning efficacy [3], increase the motivation [16], and it can support the deployment of PBL in teaching [11]. Nevertheless, the VR technology is already presented as an efficient paradigm for education $[5,11,18,33]$.

The paper posits an approach to implement a project in engineering design by leveraging 3D modeling in the form of prototyping technique as well as immersive VR platform to gauge the prototype, asses the design and promote effective communication. It also extrapolated on this approach's efficacy in influencing the performance of students as compared to a traditional approach. 
The presented CAVE display provides a wide stereoscopic view to many audiences sharing the same view simultaneously. This creates a common place for the students to discuss and share ideas while inspecting the design and promote better communication as well as advanced new style of communication between the instructor and the students that is very similar to the industry practice. The approach can be extended as hybrid PBL or even virtual labs concepts in many engineering courses.

\section{Engineering skills course}

Engineering skills is a three-credit-hours general core course for all engineering disciplines in the College of Engineering offered in each semester. The main topics in this course include introduction to engineering and engineering disciplines, communication skills, problem solving skills, and introduction to design method.

ABET students' outcomes were used to examine the achievement of the students for each approach. ABET accreditations is based on a set of standards (criteria) that the program must satisfy [1]. One of the criteria is student outcomes which entails a description of various pointers that the students must be aware of and implement by the time they complete their graduation. Table 1 illustrates the ABET students' outcomes. Notably, these outcomes include the mention of 'A to $\mathrm{K}$ ', but this study has selected only those outcomes that have mapping to the course objectives.

The course outcomes and mapping to student outcome according to ABET are outlined in Table 2 .

The teaching methodology and tools used were identical in both sections and the only difference is the project approach. The student assessment and grading were applied in both traditional approach and VR approach. This is illustrated in Table 3.

To maintain the consistency of grading of this project, a rubric for each component of the project (report, implementation, presentation) was developed and followed strictly. Each rubric for each project component was graded on a scale of four - 1 for beginning level and 4 for excellent level. The criteria for each component rubric are listed in Table 4.

The grading rubric for presentation is well defined in the literature. The rubric evaluates the students on literature review and understands each phase of the design process in addition to report writing and teamwork. The rubric for implementation stresses on the originality and creativity of the proposed design. The drawing evaluates the technical side and the usage of advanced tools and design details criteria addressed how many details were added to the design. The rubric was also designed to evaluate the course outcomes $\mathrm{f}, \mathrm{e}, \mathrm{g}, \mathrm{c}$, and i in Table 3 so as to better reflect the student's achievements. The course components are the same in both sections; only minor changes were made in the weight of report and implementation. However, the grades were normalized in accordance with Table 4 so as to facilitate data comparison.

Table 1 Abet student outcomes

Student Outcomes

e) A deep rooted understanding of ethical and professional responsibility.

f) An innate ability to identify, understand and resolve difficult engineering problems.

g) The ability of effective communication

h) The recognition of broad-based education in a broad economic, environmental and societal context

i) A recognition for the need of and the ability to undertake lifelong learning 
Table 2 Course outcome and mapping to student outcome

1. Understand the various disciplines and the role of engineer in the society

2. Describe and analyze the consequences of non-ethical or un-professional conducts.

3. Demonstrate a schematic approach for engineering problem solving.

4. Demonstrate improved communication skills

5. Apply the engineering design methodology.

6. Search for information via traditional and online sources

\section{Methodology}

The methodology is premised on a comparison made between the traditional approach undertaken in a design project and this new VR-driven approach that attempts to improve motivation as well as performance of the students. Both these approaches were implemented in varying sections during the course of different semesters. Notably, this design project primarily aims to enable students to design/develop a suitable engineering solution by following the engineering design method that is covered in detail in lectures based on textbooks [19]. The method entails the synthesis of new technologies, an examination of their performance, getting connected with the engineering teams and finally implementing the technology. This design methodology consists of 10 steps, many of which are iterative in nature and necessitate analysis, communication, and implementation (please refer to Fig. 1). This process enabled students to get involved in several essential activities such as identifying the problem, brainstorming solutions, conducting feasibility study to filter the ideas and creating preliminary design based on promising ideas. They subsequently created the design details to obtain the best idea for precision-laden drawings as well as specification. Finally, they tested and verified the solution.

The students are required to practice the entire process to master the design method; therefore, they must develop a prototype in order to apply testing and evaluation. In order to help first year engineering students to create a prototype, it is paramount that the ideas are simple enough to be easily implementable; else, it can be reduced to mere concepts with drawings without being implemented. This not only curtails the scope and difficulty level of projects, but also stifles the students' creativity and discourages them from exploring myriad approaches to fully decipher the underlying objectives. The traditional approach was essentially based on giving students several simple project ideas based on K-12 skills and asking them to develop a final prototype. Examples include a design wind powered machine, a hydraulic clock etc. This approach has been used for the past few years and we have sufficient data when it comes to understanding the students' performance.

Table 3 Course assessment components and grading weight

\begin{tabular}{ll}
\hline Course Components & Weight \\
\hline Midterm Exam & $25 \%$ \\
Final Exam & $30 \%$ \\
Homework & $10 \%$ \\
Quizzes & $10 \%$ \\
Project & $25 \%$ \\
\hline
\end{tabular}


Table 4 Criteria used in report, implementation, and presentation rubric

\begin{tabular}{lll}
\hline Report $(45 \%)$ & Implementation (35\%) & Presentation (20\%) \\
\hline Introduction & Aesthetics & Organization \\
Literature review & Drawing & Subject Knowledge \\
Synthesis & Design Details & Graphics \\
Analysis & Originality & Mechanics \\
Discussion & Creativity & Eye Contact \\
Overall Mechanics & Elaboration & Elocution \\
Teamwork & & Time Management \\
\hline
\end{tabular}

Under a VR-led approach, the first year students of engineering were provided with an idea for a project which had to be applied in a real world setting. More specifically, they were asked to undertake the design of a kitchen that facilitates the movement of those in wheelchair people, keeping in mind specific constraints with regard to room size, budget and materials. The element of safety as well as mass production was the most important parameter for this project's success. The students were required to implement all concepts of engineering design that they had learned theoretically. It is difficult to create sophisticated and detailed prototype using the traditional tools. Therefore, this proposed method entails the utilization of a widely used 3D modeling technique in order to save money and time, particularly during the design process. Students were encouraged to incorporate 3D modeling software in order to build prototypes whilst adding the finer details necessitated in real-life solutions. The approach entails a completely self-directed learning, during the entire project; at no stage was the instructor involved in providing solutions or implementing the project. In fact, even during the learning of 3D software, which is the most difficult aspect of this project, students were instructed to learn independently and build proper skills from the video tutorial freely available by SketchUP software. However, one tutorial was given to students to get them starting up by teaching them how to install and the basic principles of 3D modeling and how to use the tools to construct simple models. The students demonstrated their ability to learn by themselves and

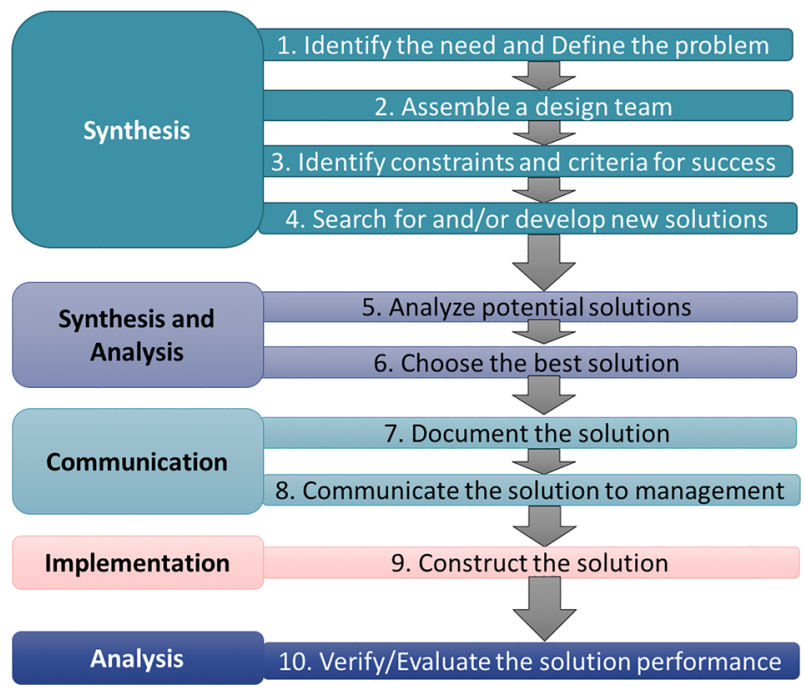

Fig. 1 The engineering design method 
went beyond expectation due to their self-interest in learning 3D modeling, animation, and texturing skills. Many believed that this is an important skill especially students from mechanical, civil, and computer engineering. The project enabled them to understand as well as implement all details relevant to an actual kitchen. Each group produced a different design and incorporated different creative ideas. An example of a 3D kitchen model for one of these project groups among total of twelve groups is shown in Fig. 2.

The 3D model had to be presented in a format which made it possible to be seen on CAVE display. Students were also instructed to ensure the model view's proper alignment with CAVE display. This was done to make sure that the viewer could stand right at the middle of this model. They enjoyed learning about the numerous nuances of 3D graphics and looked at their work (that could be viewed on the display) with a sense of accomplishment. After brainstorming, they were directed to come up with a minimum of three solutions prior to analyzing them on the basis of several criteria of constraints and success.

All the groups could test, maneuver and interact with their design. The CAVE display provided an immersive experience at a practically real-life size to make it easier for students to detect challenges that would otherwise have been almost impossible to track in $2 \mathrm{D}$ display. A real demonstration of a kitchen final design in CAVE is seen in Fig. 3, which is the same design of the 3D model presented in Fig. 2. This step turned out to be immensely beneficial as it allowed student to directly implement assessment and enhancement during the design process. During the second visit when their final design was demonstrated, students were better equipped to tackle these problems.

Although they were able to access the lab to test their prototypes, two official sessions were arranged for them to demonstrate their design on CAVE display for the instructor and the

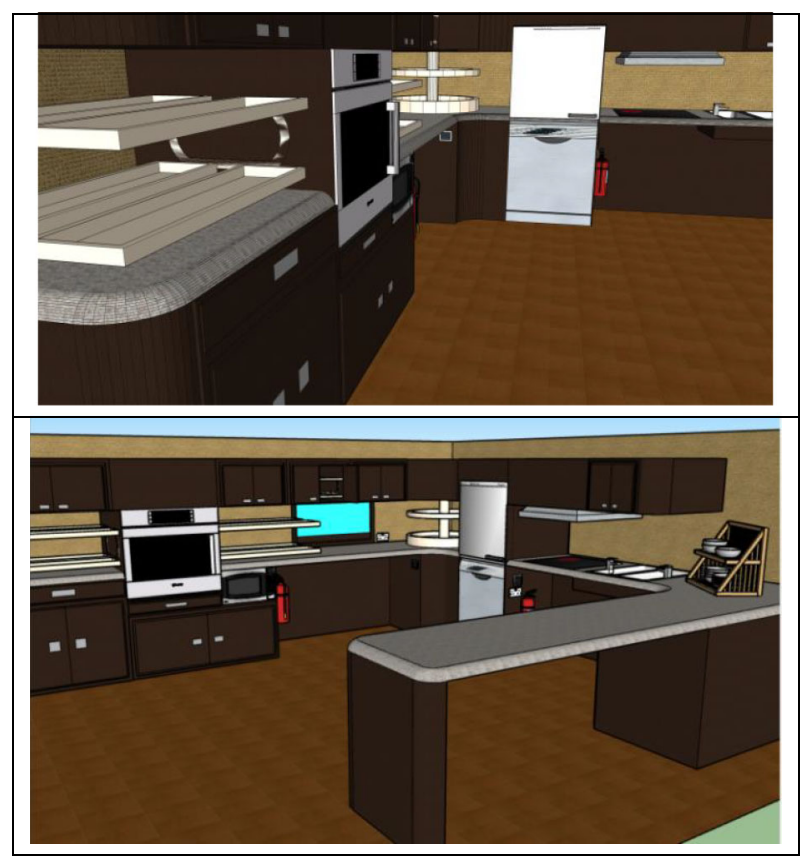

Fig. 2 A visual illustration of the kitchen's 3D model that incorporates all relevant details included by a project group using SketchUp software 


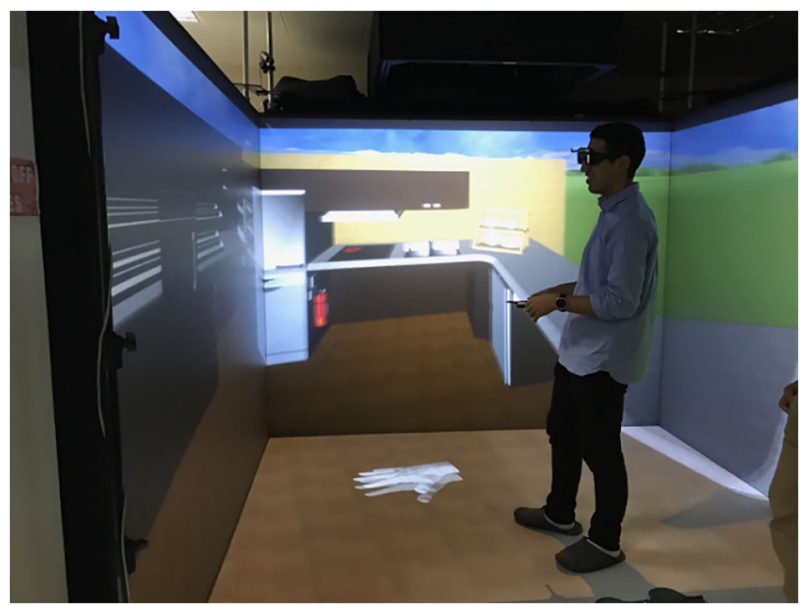

Fig. 3 A student is seen to demonstrate the final design in accordance with CAVE. Notably, the CAVE display was 3 side walls and one floor with $2.7 \mathrm{~m} \times 2 \mathrm{~m}$ dimension and equipped with tracking for head and wand to provide full interactivity

whole class. They were instructed to investigate the model and pinpoint problems during their initial visit; this had to be done by visualizing their actual presence in a kitchen. Students made this demonstration before the entire class, which prepared them better to examine different ideations whilst facilitating interactive feedback. For other students as well, this was an engaging experience since they were allowed to put on 3D glasses and obtain a firsthand experience of the design in conjunction with the presenter. Consequently, this provided a favorable environment to undertake constructive discussion and involved the whole class. The students admitted that this high fidelity, interactive display enabled them to uncover several problems that would be otherwise impossible to identify using a conventional desktop display. Also, this display provided a great platform for the students all to view the model in $3 \mathrm{D}$ and to communicate and discuss different aspects of their design that is usually difficult to achieve in other types of displays.

Furthermore, this mechanism also enabled the instructor to share meaningful feedback about how to improve the design, asking students to take these comments into consideration and think about making proactive modifications to address any underlying issues. This step was deemed as the product's initial evaluation, allowing students to undertake intelligent experiments and implement iterations quickly, which is a key element of the design process. This contrasts with the conventional approach which makes it unfeasible to redesign the project owing to time and cost constraints, but digital prototyping in VR made it easier to implement at a lesser cost. Subsequently, they were provided another chance to demonstrate the manner in which they addressed the design problems identified during the first visit.

\section{Experiments and result}

As mentioned before, students were instructed to undertake the design of a kitchen for people in wheelchair. The students were assessed by a written report, a 3D model, and a presentation delivered in front of the class. In contrast to 32 students involved in the conventional section with 10 groups, the section involving the VR approach included 35. Only those students who 
had passed the course were included. In order to facilitate subjective assessment, this study used a questionnaire to investigate key factors of difficulties related to the project and the manner in which they inspired the students to work cohesively as a team and eventually achieve course outcomes. The College of Engineering prepared and administered the questionnaire to evaluate the achievement of course outcomes. In this study, three questions related to ABET e, $\mathrm{f}$, and $\mathrm{c}$ in Table 1 and associated with the studied approach were used in order to report the result. The questions are illustrated in Table 5 and the used questions in this study are 4,5 , and 6 . The answers were provided on a scale of 1 to 4 ; with 1 indicating 'strongly agree'; 2 denoting 'agree'; 3 signifying 'disagree'; and 4 representing 'strongly disagree.' Fig. 4 depicts the response for three outcomes of strongly agree, which makes it evident that the VR approach scored higher over the traditional mechanism when it comes to helping the students perform better in achieving the learning outcomes e, $\mathrm{f}$, and $\mathrm{g}$. It is evident that VR had a significant impact on the communication process as it mostly improved with the response that had the highest percent for strongly agree and agree. Also, the ability to demonstrate problem solving was improved during the VR approach where the mean value for question 6 was 1.37 for VR approach compared to 1.87 for traditional one.

To have more insight on the impact of using the new approach on the students perception and what aspects of learning has been affected, we used another questionnaire administrated by the college to evaluate the faculty and the course teaching methodology and materials. The survey is conducted in exactly the same manner of the previously mentioned questionnaire using the same scale. The questionnaire consists of twenty questions, we selected four questions that are mostly related to the teaching mythology, level of interest in students, independent study and learning activities. The questions are illustrated in Table 6.

We can see from Fig. 5 that VR approach outperformed the traditional approach on all aspects. The enthusiasm of the students increased from 70.8 to 84.1 , the students believed more that they learned important things with increase of $19.7 \%$ from 66.7 in traditional, their interest in the subject increased from 58.3 to 81.8 with $23.5 \%$ increase which the highest impacted factor among all results. This indicates that VR approach can significantly improve the interest which will be reflected in their motivation to learn. Finally, the students felt that they were more able to carry out independent study with increment of $15.3 \%$ from 68.8 for traditional approach compared with 84.1 for the VR approach. The previous factors are important indicators to the success of teaching and students interest and it is evident that the proposed approach can make an impact on these factors which consequently improve the students' performance. This can explain why the student performance increased from qualitative evaluation.

Based on the further analysis of this questionnaire, it was concluded that the VR approach was found to be very interesting for $90 \%$ of the students. The concept of being able to interact

Table 5 Questionnaire to evaluate course outcomes

Questions about Course Outcomes

1. By the end of this course, I am able to: understand the various disciplines as well as the role of an engineer in the society.

2. By the end of this course, I am able to: describe and analyze the consequences of non-ethical or un-professional conduct.

3. By the end of this course, I am able to: search for information through conventional and online sources.

4. By the end of this course, I am able to: implement the engineering design methodology.

5. By the end of this course, I am able to: exhibit enhanced communication skills.

6. By the end of this course, I am able to: implement a schematic approach to solve engineering problems. 


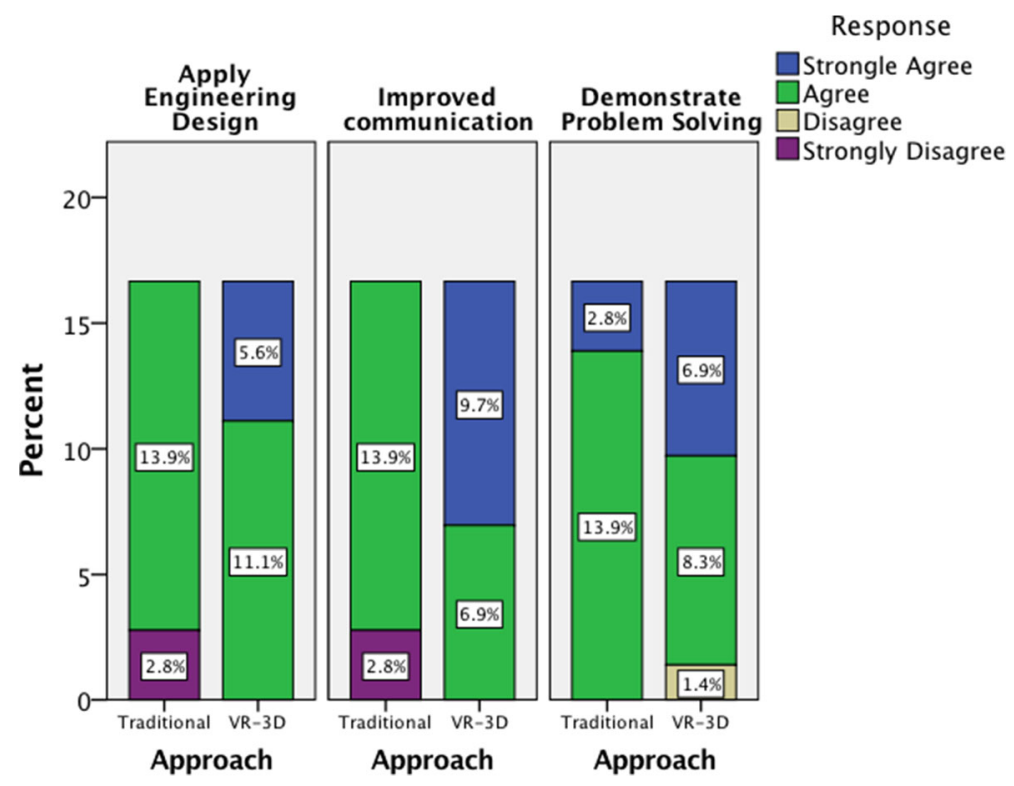

Fig. 4 Evaluation of the course outcomes for traditional and VR approach

in a $3 \mathrm{D}$ virtual environment that the students had created by themselves was very appealing to them. They felt a sense of accomplishment and because it would not be just another abstract idea that would remain unimplemented on paper. The survey included two questions regarding the portions that were easy and difficult whilst completing the project. Students mentioned that they found learning 3D modeling to be the most difficult part; this could be made easier for them by providing additional help in the form of a teaching assistant. Regarding the number of failed students, it has been found that three students failed in traditional approach section compared to one student in VR approach section (66.6\% improvement) which can be considered as another positive indicator.

In each section, the grade of these students was incorporated to make a comparative assessment of both approaches. These grades were divided into three groups: (1) cumulative course grading for all components of the course; (2) project grade restricted to project components; and (3) grade for all components, barring the project.

Figure 6 shows the result of these three grades for conventional as well as VR approach, showing that the mean of project grade and cumulative grade increased following the implementation of VR approach. A hypothesis test is required to test the statistical importance of the result. A non-parametric hypothesis test that is robust for data that is not normally distributed is needed since the grade distribution is not entirely normal. In this case, Mann-

Table 6 Questionnaire to evaluate course teaching

1. Course content delivery and teaching methods generated my enthusiasm for learning the subject matter.

2. I learned important things in this course.

3. My interest in the subject matter has increased after taking this course.

4. Students were encouraged to do some independent study or to explore different viewpoints. 


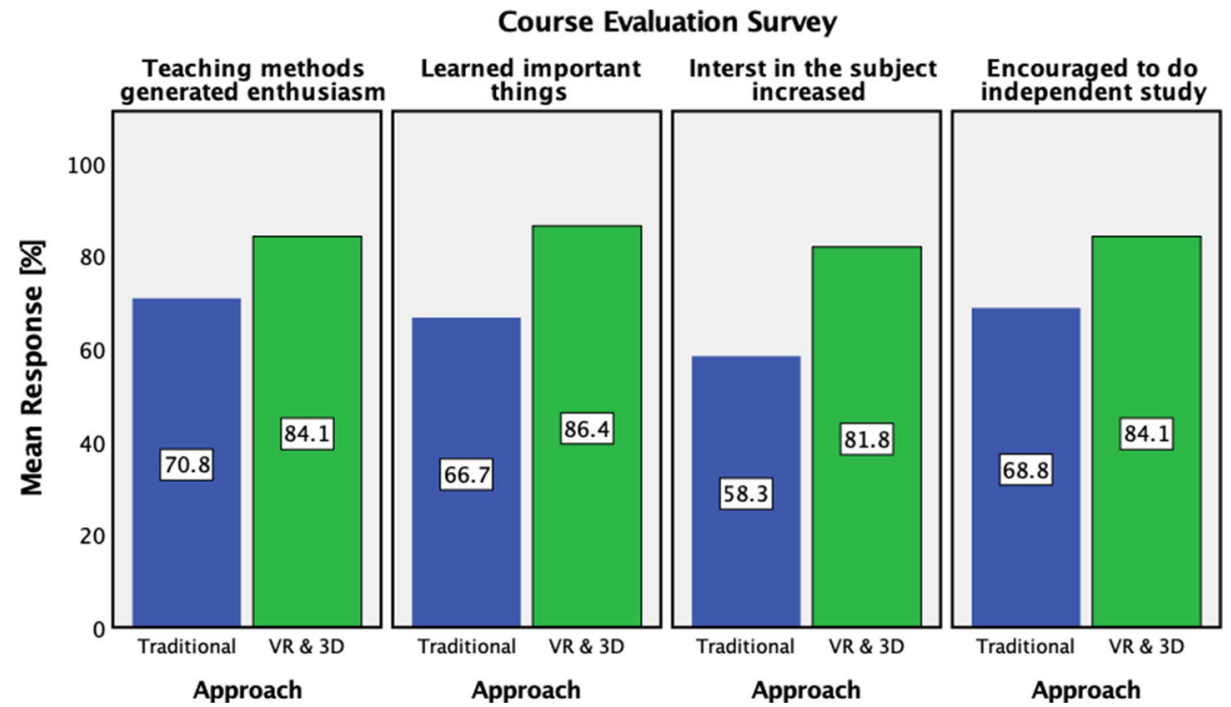

Fig. 5 Evaluation of the course teaching methodology for traditional and VR approach

Whitney-Wilcoxon was opted for because of its robustness with regard to the lack of normally distributed data as well as its efficiency on data that was distributed normally.

Table 7 show the result of the MWW test related to all three grades at a $95 \%$ confidence interval. For both sections, the project grade illustrated that the median value stood at 78.3 out of 100 for students using the conventional approach; this value was 91 for those using the VR approach. This mean value was also seen to rise from 80.7 to 92.8. The $p$ value for MWW test

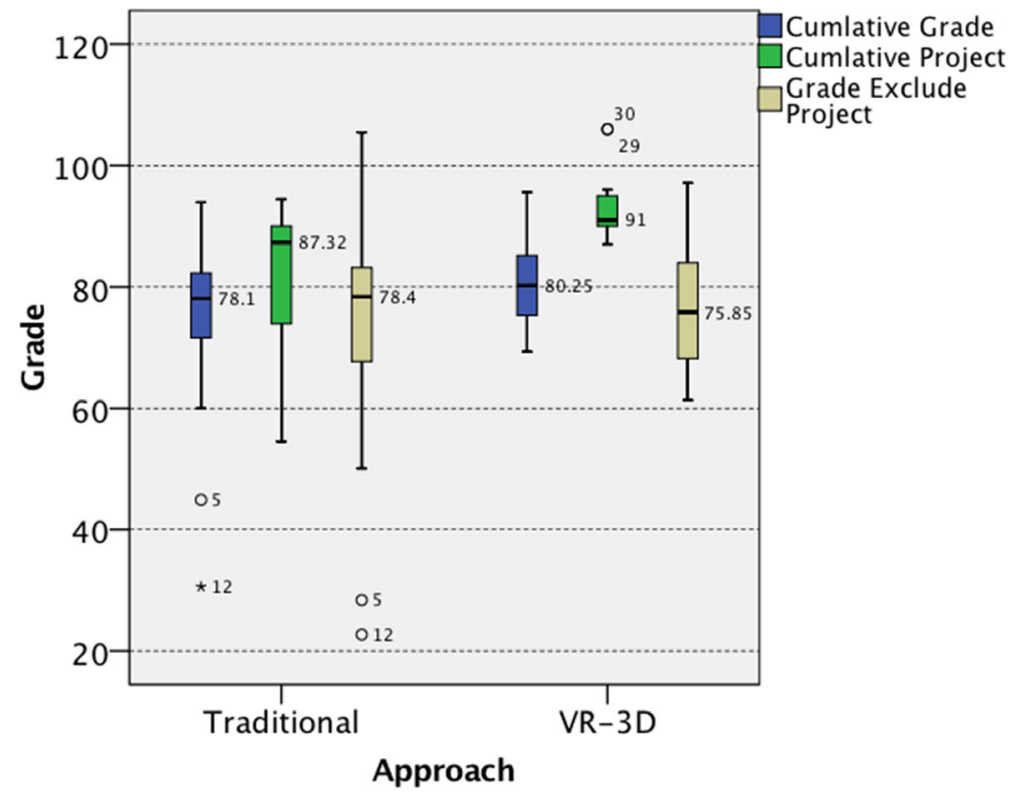

Fig. 6 Boxplot of student grade for student project grade, cumulative grade, and grade for all courses, barring the project for both VR approach and traditional approach 


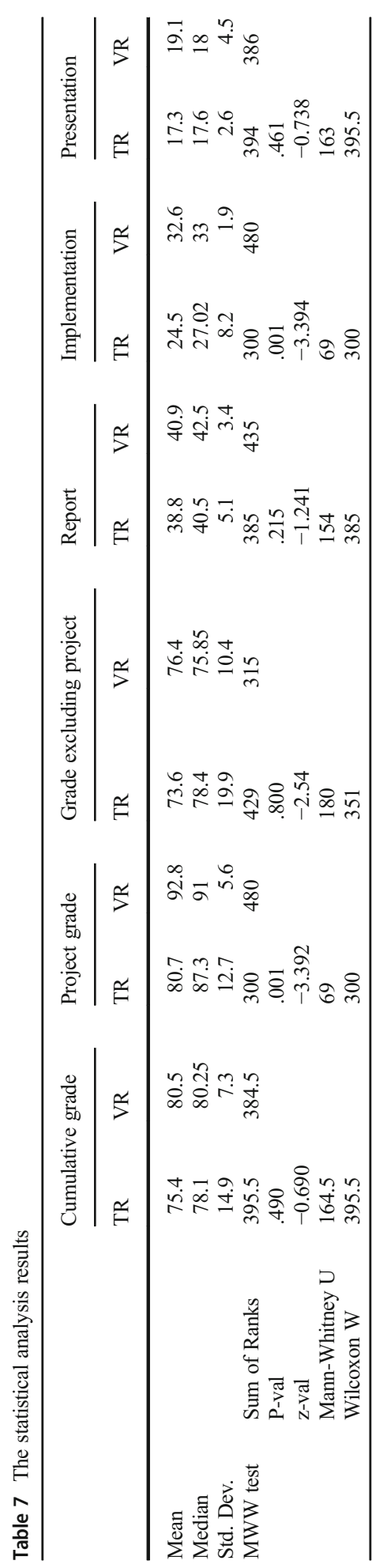


is 0.001 which is adequate for rejecting the null hypothesis. Thus, it can be inferred that the VR approach caused a significant improvement in the project grade.

The median of the cumulative course grade improved slightly from 78.1 to 80.5 , and the mean increased from 75.4 to 80.5. However, the above MWW test resulted in a $p$ value of 0.490 - sufficient enough for retaining the null hypothesis. Thus, the VR approach did not make significant changes on the distribution of the cumulative grade. In other words, the new project approach did not decrease the student grade, so the student performance will not be affected negatively. Looking into the grade for all components of the course except this project, the median reduced from 78.4 to 75.85 but the mean increased from 73.4 to 76.4 . According to the MWW test, the $p$ value stood at 0.800 . This indicates the absence of any significant changes in the grade for all courses after the exclusion of the project.

To further understand the impact of this approach on each component of the project itself, the grades were analyzed for each component in both approaches. The boxplot of grades in Fig. 7 illustrates that the median of the report increased slightly from 40.5 to 42.5 , and that the median of implementation increased from 27.02 to 33; also, the median of presentation increased slightly from 17.6 to 18 . However, the hypothesis can be retained for both report and presentation with $p$ value of 0.215 and 0.461 and rejected for implementation for $p$ value of 0.001 , which also confirm that the implementation improved significantly after VR approach.

\section{Discussion}

VR technology moved from being the technology of future in science fiction movies to an established technology in many sectors. Many large companies like Siemen, Jaguar, and Arup

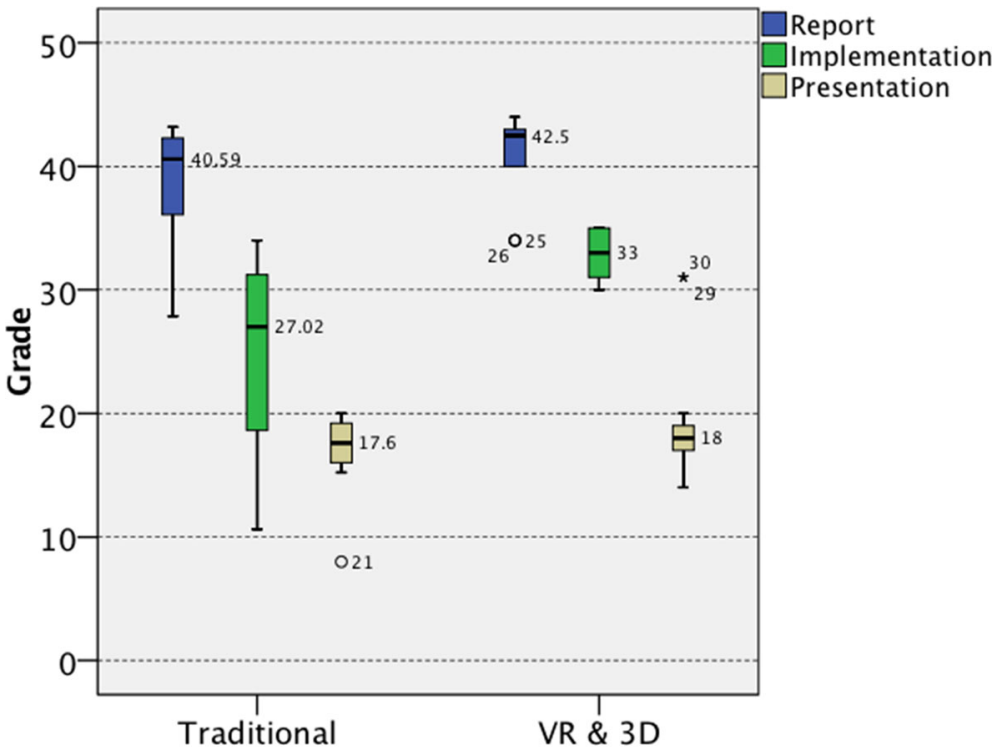

Approach

Fig. 7 Boxplot of student grade for each component of the project grade 
are using VR immersive technology to transfer their engineering processes [27]. VR is already being used in industrial design and design engineering to generate product prototypes for automotive and aerospace which is very similar to what the approach proposed in this paper. Immersive VR enable engineers to visualize these prototypes, walk and interact to improve the design or identify and fix issues in the product before a physical prototype is made. In construction VR is expected to impact the design and construction practice as it can provides easy visualization. Electrical appliances can use VR to check the exact storage and demonstrate the appliances and get better marketing feedback. Moreover, it provides safer and more effective training for engineering. Above all, VR can revolutionize the collaboration between teams where engineers in remote locations can work together. This is one of the challenges that VR is addressing where we can see many systems that enable such collaboration. The future for VR is promising but there several engineering hurdles before being able to fully simulate reality effectively. The resolution of the display must be high enough, with fast update rate to avoid cybersickness. Also, the field of view must be wide enough with realistic simulation of the lighting and shadows which need high processing power. Above all, we need to reproduce different sensation like touch, sound, and motion. Training the students on such a skill will be indispensable for engineering industry.

As an improved teaching-learning environment, the utilization of VR and 3D software can provide students of engineering with excellent tools to examine, design as well as develop new concepts. This approach can be utilized effectively in developing a conceptual framework for engineering design using VR. In this work, VR was only used for evaluation due to constraints in making immersive VR available for all students at any given point in time. However, VR can also be utilized during the design process by using new affordable VR headsets like Oculus Rift, HTC vive, and recently low-cost Oculus Go, which provides the benefit of high resolution and stand-alone portable whilst obviating the need for PC or cables. Many headsets can be provided all the time to students in designated labs to enable them to utilize VR during the whole engineering design process; the students can also purchase this headset easily as it costs less $\$ 200$. The suggested framework can be an extension of the presented steps by making evaluation easily available for students to test and evaluate their designed artifacts in addition to the different phases of design at any time. The first step is denoted by ideation where the students are asked to produce at least three potential ideas or solutions, before using analysis mechanisms, such as advantage matrix before selecting one of the best solutions. Repetitive implementation, testing, and evaluation phases using 3D modeling software and VR environment and headset is also utilized. There is still a need to come up with more robust evaluation rubrics of the students' attainment of learning objectives using such an approach. The advantage of this framework is it enables the designer to visualize, analyze, optimize, and test the product.

\section{Conclusion}

In summation, it can be safely concluded that VR has the potential of being used as an effective tool for education. Against this backdrop, the research study assessed the provision of design component within the overarching theme of an engineering course in order to teach design skills via a PBL methodology. In this approach, a virtual prototype was implemented in a VR environment that was fully immersive. The evaluation of VR approach is predicated on the students' achievement of project goals. The result demonstrated a significant effect of using 
VR in increasing the cumulative project grade and specifically on the implementation component of the project in addition to enhancing the engagement and motivation of these students and better achievement of the course outcomes.

Given that this approach can be implemented without necessitating prior skills, it becomes a very attractive proposition especially for students. This also builds on the growing body of studies on how VR can be used successfully within the Science, Technology, Engineering and Mathematics (STEM) curricula, especially with recent availability of very low cost and standalone VR headset. In recent studies, recommendations have been made to incorporate Art and Design in order to foster both reasoning and creativity. This signals the gravitation towards a new system that includes Science, Technology, Engineering, Mathematics and Arts \& Design (STEAM) [31]. This concept stressed on the significance of encouraging the growth of engineering professionals in the long term, especially due to the fact that engineers are required to constantly adapt to the evolving realities of workplace in an inherently fluid ecosystem.

Recent advancements in VR technology have augmented the quality of visualization whilst also making it more affordable. This positions VR as a feasible alternative to the conventional method of teaching. Moreover, it can be a robust tool to test as well as evaluate new products. The results of this research demonstrated the efficiency with which the students were able to interact with the environment and visualize their design challenges.

Funding Information Open Access funding provided by the Qatar National Library.

Open Access This article is distributed under the terms of the Creative Commons Attribution 4.0 International License (http://creativecommons.org/licenses/by/4.0/), which permits unrestricted use, distribution, and reproduction in any medium, provided you give appropriate credit to the original author(s) and the source, provide a link to the Creative Commons license, and indicate if changes were made.

\section{References}

1. ABET (2017) 2016-2017 Criteria for Accrediting Engineering Programs

2. Abulrub AG, Attridge A, Williams MA (2011) Virtual reality in engineering education: The future of creative learning. Int J Emerg Technol Learn 6(4):4-11

3. Ai-Lim Lee E, Wong KW, Fung CC (2010) How does desktop virtual reality enhance learning outcomes? A structural equation modeling approach. Comput Educ

4. Andersen INSK, Kraus AA, Ritz C, Bredie WLP Desires for beverages and liking of skin care product odors in imaginative and immersive virtual reality beach contexts. Food Res Int 2018

5. Barata PNA, Filho MR, Nunes MVA (2015) Consolidating Learning in Power Systems: Virtual Reality Applied to the Study of the Operation of Electric Power Transformers. IEEE Trans Educ

6. Kolmos, A. (2009). Problem-based and project-based learning. In O. Skovsmose, P. Valero, \& O. R. Christensen (Eds.), University science and mathematics education in transition. Heidelberg: Springer

7. Becker JP, Plumb C, Revia RA (2014) Project circuits in a basic electric circuits course. IEEE Trans Educ 57(2):75-82

8. Bell S (2010) Project-Based Learning for the 21st Century: Skills for the Future. Clear House 83:39-43

9. Boy GA (2013) From STEM to STEAM: Toward a Human-Centered Education. Eur Conf Cogn Ergon:8

10. Chuah KM, Chen CJ, Siong Teh C, Chuah KM, Chen CJ, Teh CS. Incorporating Kansei Engineering in instructional design: Designing virtual reality based learning environments from a novel perspective. Klidarithmos Computer Books.

11. de Oliveira FS, Santos S (2016) PBLMaestro: A virtual learning environment for the implementation of problem-based learning approach in Computer education. In: 2016 IEEE Frontiers in Education Conference (FIE)

12. Falcao CS, Soares MM (2015) Application of Virtual Reality Technologies in Consumer Product Usability. 9186:342-351 
13. Froyd JE (2011) Problem-based learning and adaptive expertise. In: 2011 Frontiers in Education Conference (FIE), pp. S3B-1-S3B-5.

14. Gomes de Sá A, Zachmann G (1999) Virtual reality as a tool for verification of assembly and maintenance processes. Comput Graph 23(3):389-403

15. Guerlesquin J, Mahdjoub G, Bazzaro M, Sagot F (2012) Virtual reality as a multidisciplinary convergence tool in the product design process. Syst Cybern Informatics 10(1):51-56

16. Häfner P, Häfner V, Ovtcharova J (2013) Teaching methodology for virtual reality practical course in engineering education. Procedia Computer Science

17. Halabi O, Abou El-Seoud MSS, Geroimenko V (2018) Teaching Design Project in Introductory Engineering Course Using 3D Modeling and Immersive Virtual Reality. Advances in Intelligent Systems and Computing 716:27-36

18. Harms S, Hastings $\mathrm{J}$ (2016) A cross-curricular approach to fostering innovation such as virtual reality development through student-led projects. In 2016 IEEE Frontiers in Education Conference (FIE), pp. 1-9

19. Holtzapple MT, Reece D (2007) Concepts in Engineering, 2nd Ed. McGraw-Hill

20. Jette S (2012) The Third Industrial Revolution- How Lateral Power Is Transform-ing Energy, The Economy, and the World. World Future Review (World Future Society) 4(2):199-202

21. Kim TJ, Huh JH, Kim JM (2018) Bi-directional education contents using VR equipments and augmented reality. Multimed Tools Appl

22. Laseinde OT, Adejuyigbe SB, Mpofu K, Campbell HM (2016) Educating tomorrows engineers: Reinforcing engineering concepts through Virtual Reality (VR) teaching aid. In: IEEE International Conference on Industrial Engineering and Engineering Management

23. Lee MJW, Nikolic S, Vial PJ, Ritz C, Li W, Goldfinch T (2016) Enhancing Project-Based Learning Through Student and Industry Engagement in a Video-Augmented 3-D Virtual Trade Fair. IEEE Trans Educ

24. Lee EA-L, Wong KW (2008) A Review of Using Virtual Reality for Learning.

25. Liang W (2019) Scene art design based on human-computer interaction and multimedia information system: an interactive perspective. Multimed Tools Appl 78(4):4767-4785

26. Martínez F, Herrero LC, De Pablo S (2011) Project-based learning and rubrics in the teaching of power supplies and photovoltaic electricity. IEEE Trans Educ 54(1):87-96

27. Rivera A (2018) How Virtual Reality Is Changing Engineering. WwwBusinessCom, no (70)

28. Saorín JL, Melian-Díaz D, Bonnet A, Carbonell Carrera C, Meier C, De La Torre-Cantero J (2017) Makerspace teaching-learning environment to enhance creative competence in engineering students. Think Skills Creat

29. Sattar MU, Palaniappan S, Lokman A, Hassan A, Shah N, Riaz Z (2019) Effects of Virtual Reality training on medical students' learning motivation and competency. Pakistan J Med Sci 35(3):852-857

30. Seo JH, Bruner M, Payne A, Gober N, McMullen D“R”, Chakravorty DK (2019) Using Virtual Reality to Enforce Principles of Cybersecurity. J Comput Sci Educ 10(1):81-87

31. Sochacka NW, Guyotte KW, Walther J (2016) Learning Together: A Collaborative Autoethnographic Exploration of STEAM (STEM + the Arts) Education. J Eng Educ 105(1):15-42

32. Tan S, Shen Z. Hybrid Problem-Based Learning in Digital Image Processing: A Case Study

33. Valdez MT, Ferreira CM, Barbosa FPM. 3D Virtual Laboratory for Teaching Circuit Theory-A Virtual Learning Environment (VLE)

34. Valdez MT, Ferreira CM, Martins MJM, Barbosa FPM (2015) 3D virtual reality experiments to promote electrical engineering education. In 2015 International Conference on Information Technology Based Higher Education and Training (ITHET), pp. 1-4

35. Yang JC, Chen $\mathrm{CH}$, Chang Jeng M (2010) Integrating video-capture virtual reality technology into a physically interactive learning environment for English learning. Comput Educ

36. Youssef BB, Berry B, Sjoerdsma M (2012) Teaching first-year interdisciplinary students to use computational design software in a spatial thinking course. In: Proceedings of the 2nd Interdisciplinary Engineering Design Education Conference, IEDEC 2012

Publisher's note Springer Nature remains neutral with regard to jurisdictional claims in published maps and institutional affiliations. 


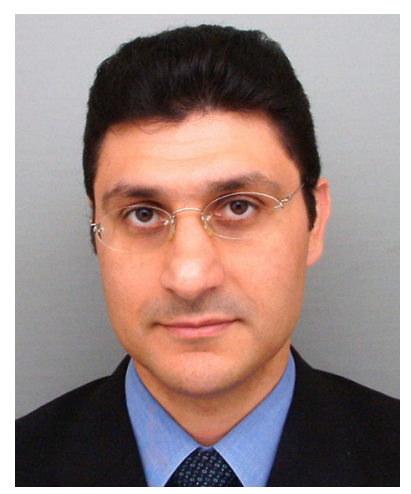

Osama Halabi received his Ph.D. in information science from Japan Advanced Institute of Science and Technology (JAIST) in 1992. He was the Fujitsu Endowed Chair (Fujitsu Co.,) at Japan Advanced Institute of Science and Technology from 2001 to 2003, a researcher at the Virtual Systems Laboratory at Gifu University from 2003 to 2006, and an assistant professor at Iwate University, Japan, from 2006 to 2010. He is currently assistant professor at Qatar University. His research interests include virtual reality, haptic interface, human - computer interaction, game development, and computer graphics. He is a member of the Virtual Reality Society of Japan (VRSJ), IEEE Technical Committee on Haptics (TCH), the IEEE Computer Society, the ACM, and The Society for Art and Science. 